\title{
Effect of Complexation on the Accumulation and Elimination Kinetics of Cadmium and Ciprofloxacin in the Earthworm Eisenia fetida
}

\author{
Bei Wen,* Rixiang Huang, Peng Wang, Yanping Zhou, Xiao-quan Shan, and Shuzhen Zhang \\ State Key Laboratory of Environmental Chemistry and Ecotoxicology, Research Center for Eco-Environmental Sciences, \\ Chinese Academy of Sciences, Beijing 100085, China
}

Supporting Information

ABSTRACT: Land application of solid wastes leads to the accumulation of both metals and antimicrobials in soils. To understand the effects of metal and antibiotic interaction on their accumulation by the earthworm Eisenia fetida, uptake and elimination kinetics and subcellular distribution of cadmium (Cd) and ciprofloxacin (CIP) were determined. The kinetics was accurately described by a one-compartment first-order kinetic model. Bioaccumulation kinetics and subcellular distribution of CIP were not affected by $\mathrm{Cd}$ addition. However, Cd exhibited different metabolic and subcellular distribution patterns. With CIP, Cd uptake flux and elimination rate constants were about 2.2 and 9.8 times, respectively, those without CIP. In the presence of CIP, Cd redistributed from fractions $\mathrm{D}$ (associated with granules) and $\mathrm{E}$ (associated with tissue fragments and cell membranes) to fraction $\mathrm{C}$ (associated with cytosol). Without CIP, Cd in fraction $\mathrm{C}$ could not be excreted, whereas with

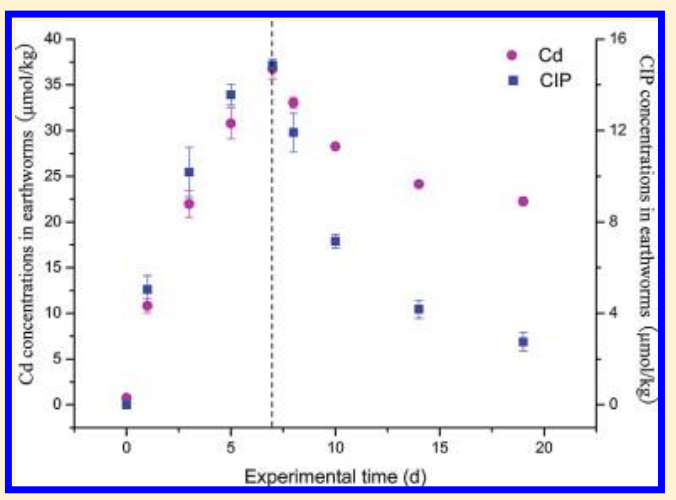
CIP, Cd in fraction $\mathrm{C}$ was significantly excreted, and the excretion rate constant was consistent with that of CIP. A good relationship was found between CIP and Cd in earthworms during uptake and elimination periods $(p<0.01)$. Our results indicated that the Cd-CIP complex may be taken up, stored, and eliminated by earthworms.

\section{INTRODUCTION}

Application of municipal, agricultural, and industrial solid waste to agricultural soils is becoming an increasingly important global practice to enhance and sustain soil organic matter and fertility levels. However, this practice possesses potential risks associated with contaminant accumulation in surface soils. One of the main concerns is the varying amounts of heavy metals in solid wastes, such as $\mathrm{Cd}, \mathrm{Cr}, \mathrm{Cu}, \mathrm{Pb}, \mathrm{Ni}$, and $\mathrm{Zn} .{ }^{1,2} \mathrm{In}$ addition, solid wastes from intensive farming and treated sewage are known to contain significant levels of antibiotics. These antibiotics are assumed to be highly persistent in the environment, ${ }^{3}$ leading to the accumulation in the terrestrial environment. ${ }^{4}$

Antibiotics usually are polyprotic substances with many protonatable groups that can bind metals. This complex formation plays an important role in the bioavailability and pharmacodynamics of antibiotics. ${ }^{5}$ The decreases of ciprofloxacin (CIP) intestinal absorption due to the interaction between CIP and metal ions ( $\mathrm{Al}$ and $\mathrm{Mg}$ ) has been reported. ${ }^{6}$ The complexation between antibiotics and metal ions also affects the speciation of metals, which is suggested to be related to metal bioavailability. Although extensive research has been conducted to correlate the speciation and bioavailability of metals, inconsistent and even contradictory results were frequently reported. For example, Bayen et al. ${ }^{7}$ found that the presence of complexing agents decreased the uptake of $\mathrm{Cd}$, implying that only free $\mathrm{Cd}$ ion $\left(\mathrm{Cd}^{2+}\right)$ contributes to $\mathrm{Cd}$ bioavailability, whereas results obtained by Degryse et al. ${ }^{8}$ showed that the presence of ligands increased the uptake of $\mathrm{Cd}$ by spinach. These divergences may be due to the different nature of the complexes. Currently little is known about the effects of antibiotic being a complexing agent on the bioavailability of metal, especially to nontarget species.

The accumulation of pollutants is a dynamic process consisting of uptake, partition, storage, and excretion, which is influenced by biological (target organism or organ) and geochemical (physicochemical properties of the medium and the pollutants) factors. ${ }^{9}$ The changes of the species of antibiotics and metals may influence their metabolism in an organism. It was shown in our previous work that CIP affects the accumulation, subcellular distribution, and toxicity of $\mathrm{Cu}$ to the earthworm, probably due to the uptake of intact $\mathrm{Cu}-\mathrm{CIP}$ complex. ${ }^{10}$ Since the bioaccumulation of different metals differs even for the same organism, especially between essential and nonessential metals, ${ }^{11,12}$ research is needed to understand the effects of CIP complexation on the bioaccumulation of nonessential metals such as $\mathrm{Cd}$.

Due to the accumulation, the coexistence, and the interaction between antibiotics and metals, it is necessary to assess their combined effects on the terrestrial environment. Earthworms comprise the largest part of the soil fauna biomass and are able to accumulate various organic and inorganic contaminants. ${ }^{13}$

Received: December 1, 2010

Accepted: April 5, 2011

Revised: April 5, 2011

Published: April 22, 2011 
Accumulation of contaminants implies a risk to not only earthworm populations but also many vertebrate species feeding on earthworms. Therefore, the aim of the present study was to understand the effects of the complexation on the CIP and Cd uptake and elimination kinetics and subcellular distribution in Eisenia fetida earthworms when exposed to quartz sand. Quartz sand does not bind any Cd and CIP from solution; thus, it is estimated that in this study the accumulation of $\mathrm{Cd}$ and CIP by earthworms is primarily from pore water.

\section{MATERIALS AND METHODS}

Reagents. The exposure solutions of $\mathrm{Cd}$ and/or CIP were prepared by dissolving the $\mathrm{CdCl}_{2} \cdot 5 \mathrm{H}_{2} \mathrm{O}$ (reagent grade, Beijing Chemical Reagent Co.) and CIP (purity >99\%, Zhejiang Guobang Pharmaceuticals Co.) into deionized water. Solutions were prepared weekly or daily depending on their concentrations.

All organic solvents, such as acetonitrile, methanol, and formic acid (Sigma-Aldrich, St. Louis, MO), were of residue analysis grade. Purified Milli-Q water (Millipore Corp., Bedford, MA) was used throughout. $\mathrm{HClO}_{4}$ and $\mathrm{HNO}_{3}$ were of guaranteed reagent grade, and all other reagents were of analytical reagent grade (purity $>99 \%$ ). All glassware and plastic containers were soaked in $5 \%(\mathrm{v} / \mathrm{v}) \mathrm{HNO}_{3}$ for at least $12 \mathrm{~h}$ and thoroughly rinsed initially with tap water and subsequently with deionized water before use.

Earthworms. Mature (clitellate) Eisenia fetida earthworms were purchased from the Agricultural University of China (Beijing, China) and maintained in a laboratory culture box $(54 \mathrm{~cm} \times 40 \mathrm{~cm} \times 30 \mathrm{~cm})$ filled with sterilized loam and peat moss (50:50, fresh weight) (Changbaishan Ltd., China) at $22 \pm$ $2{ }^{\circ} \mathrm{C}$ for at least two weeks before use. The wet weight of an individual earthworm was on average $500 \pm 20 \mathrm{mg}(n=30)$. Earthworms were allowed to depurate for $24 \mathrm{~h}$ on moist filter paper before the experiment was commenced. Earthworms were kept in the dark during all tests.

Accumulation and Elimination of CIP and Cd. Earthworms were exposed to a $500 \mathrm{~mL}$ glass beaker containing $400 \mathrm{~g}$ of rinsed quartz sands (mean diameter of $1 \mathrm{~mm}$ ) and $100 \mathrm{~mL}$ of aqueous solution containing various $\mathrm{Cd}$ and CIP concentrations. The $\mathrm{pH}$ of the test solution was adjusted to $6.0 \pm 0.1$ using $\mathrm{NaOH}$ or $\mathrm{HNO}_{3}$. The quartz sands and solution had been equilibrated for 1 day. Earthworms exposed to the quartz sand with Milli-Qwater $(\mathrm{pH}$ 6.0) were used as a blank. Three serial experiments were carried out. The earthworms were treated with $100 \mu \mathrm{M}$ CIP, $50 \mu \mathrm{M} \mathrm{Cd}$, and a mixture of $100 \mu \mathrm{M} \mathrm{CIP}$ and $50 \mu \mathrm{M} \mathrm{Cd}$, respectively. No significant adsorption of $\mathrm{Cd}$ or CIP on quartz sands was found. The containers were percolated with fresh test solution saturated sands every day to maintain a consistent pore solution concentration and to prevent a buildup of complexing exudates. There were 20 containers for each treatment, and each container held seven worms. Earthworms were randomly sampled after $0,1,3,5,6$, and $7 \mathrm{~d}$ to study the uptake kinetics. Remaining earthworms were then transferred into uncontaminated containers that renewed daily with deionized water over the excretion phase of the experiment. Earthworms were randomly sampled after $8,9,10,14$, and $19 \mathrm{~d}$ to study the excretion kinetics. The collected earthworms were rinsed thoroughly for 5 min using deionized water and then weighed and frozen at $-18^{\circ} \mathrm{C}$.

Fractionation and Determination of Cd in Earthworms. Three earthworms were randomly picked to make one sample, and four replicates were carried out for each experimental point. Fractionation was performed following the protocol described by Vijver. ${ }^{10}$ Briefly, earthworms were thawed and homogenized in $5.0 \mathrm{~mL}$ of ice-cold $0.01 \mathrm{M}$ Tris- $\mathrm{HCl}$ buffer $(\mathrm{pH} 7.5$, Fisher Scientific, Houston, TX). Homogenates were then centrifuged at $10000 \mathrm{~g}$ for $30 \mathrm{~min}$ at $4{ }^{\circ} \mathrm{C}$. The supernatant belonged to the cytosolic fraction (fraction $\mathrm{C}$ ). Pellet fractions were boiled at $100{ }^{\circ} \mathrm{C}$ for $2 \mathrm{~min}$ and then hydrolyzed at $60-70{ }^{\circ} \mathrm{C}$ with $0.5 \mathrm{M}$ $\mathrm{NaOH}$. The granule fractions (fraction $\mathrm{D}$ ) could be separated from the tissue fragments, cell membranes, and intact cells (fraction E) by centrifugation at $10000 \mathrm{~g}$ for $10 \mathrm{~min}$ at $4{ }^{\circ} \mathrm{C}$. Centrifugation was performed with a Hitachi CR-22 centrifuge with an R20A rotor.

Determination of CIP in Earthworms and Earthworm Fractions. Ciprofloxacin was extracted from earthworms and earthworm fractions and purified as described previously. ${ }^{10}$ Briefly, the earthworms were thawed and homogenized. The CIP in earthworms was extracted with $0.05 \mathrm{M}$ phosphate buffer $(\mathrm{pH} 7.4)$ and cleaned with an Oasis HLB cartridge $(6 \mathrm{~mL} / 300$ mg, Waters, Milford, MA).

All measurements were performed using a 1200 LC instrument equipped with a gradient pump and fluorescence detector (Agilent Technologies, Wilmington, DE). HPLC separations were conducted using an injection volume of $20 \mu \mathrm{L}$ and linear gradient elution as follows: from $90 \% \mathrm{~A}$ (0.1\% formic acid, $\mathrm{pH}$ 2.8 ) and $10 \% \mathrm{~B}$ (acetonitrile) to $85 \% \mathrm{~A}$ and $15 \% \mathrm{~B}$ in $8 \mathrm{~min}$, returning to the initial conditions in $3 \mathrm{~min}$. The excitation and emission wavelengths for detection were 280 and $450 \mathrm{~nm}$, respectively. The chromatographic separation was carried out in an Atlantis-dC18 ODS HPLC column (4.6 i.d. $\times 150 \mathrm{~mm}$, $5 \mu \mathrm{m}$ ) (Waters). Under these HPLC conditions, CIP showed a single peak at a retention time of $8.5 \mathrm{~min}$.

Determination of the $\mathrm{Cd}^{2+}$ Concentration in Pore Water. Ion-selective electrodes (ISEs) in combination with a voltmeter of $0.1 \mathrm{mV}$ resolution (model 9629, Orion Research, Cambridge, $\mathrm{MA})$ were used to measure $\mathrm{Cd}^{2+}$ concentrations. A Cd ionselective electrode (Cd-ISE) $\left(10^{-8}\right.$ to $\left.0.1 \mathrm{M}\right)$ and a reference electrode were calibrated using the inspired water. A linear response of the Cd-ISE was obtained. The Cd-ISE was activated in $1 \mathrm{~N} \mathrm{Cd}\left(\mathrm{NO}_{3}\right)_{2}$ for $2 \mathrm{~h}$ and rinsed with Milli-Q water before use. The limit of detection was $0.6 \mu \mathrm{M} \mathrm{Cd}^{2+}$. The activity of $\mathrm{Cd}^{2+}$ at each calibration point was calculated using the speciation program ChemEQL based on the total $\mathrm{Cd}$ concentration together with other parameters, including the $\mathrm{pH}$, alkalinity, and major ion concentrations constituting inputs to the model.

Determination of $\mathrm{Cd}$ in Earthworms and Earthworm Fractions. The total $\mathrm{Cd}$ contents in earthworms and earthworm fractions were analyzed after sample digestion with $3 \mathrm{~mL}$ of concentrated $\mathrm{HNO}_{3}-\mathrm{HClO}_{4}(2: 1, \mathrm{v} / \mathrm{v})$ under high-pressure conditions. $\mathrm{Cd}$ concentrations were determined by inductively coupled plasma mass spectrometry (ICP-MS; Agilent Technologies, Santa Clara, CA). The limit of detection for Cd was 0.016 $\mu \mathrm{g} \mathrm{L}^{-1}$.

Modeling. In this experiment, the masses of the earthworms were measured. The concentrations of Cd and CIP in the earthworms (including subcellular fractions) were expressed as $\mu \mathrm{mol} / \mathrm{kg}$ wet weight and corrected for the earthworm mass changes during the exposure experiment. Quadruplicate tests were used for statistical analysis of CIP and Cd accumulation kinetics.

It was shown that accumulation of metals by earthworms can be described by a one-compartment model. ${ }^{14}$ To model Cd and 


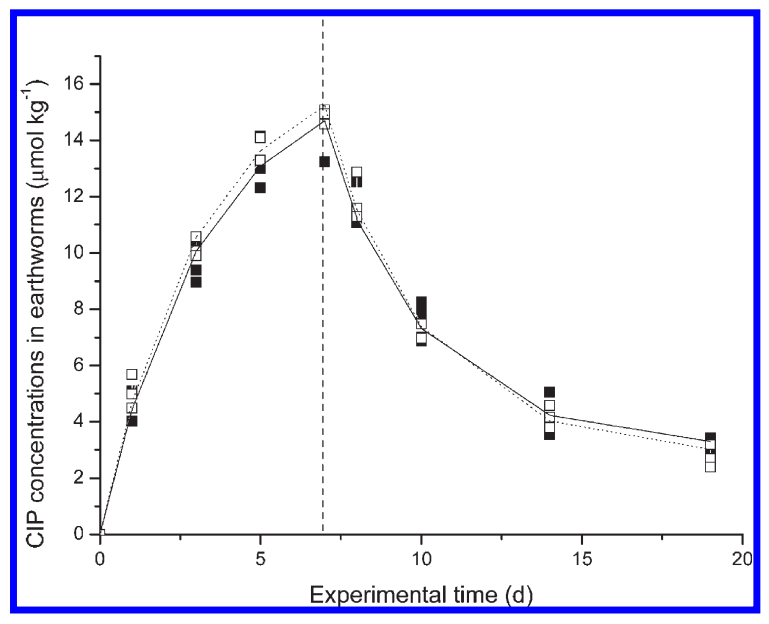

Figure 1. Accumulation and elimination kinetics of ciprofloxacin in earthworms in the absence (solid squares) and in the presence (open squares) of Cd. Solid line: fits to eqs 1 and 2 for the uptake and elimination in the absence of $\mathrm{Cd}$, respectively. Dotted line: fits to eqs 1 and 2 for the uptake and elimination in the presence of $\mathrm{Cd}$, respectively.

CIP accumulation and calculate their uptake and excretion rates over both the uptake and excretion phases of the experiment, the experimental data were fitted with the following equation along with eq 2 below:

$$
Q_{t}=Q_{0}+\alpha / k_{\mathrm{e}}\left(1-\mathrm{e}^{-k_{\mathrm{e}} t}\right)
$$

where $Q_{t}$ is the total concentration of CIP and/or Cd $(\mu \mathrm{mol}$ $\mathrm{kg}^{-1}$ worm $)$ in earthworms at time $t(\mathrm{~d}), k_{\mathrm{e}}$ is the excretion rate constant $\left(\mathrm{d}^{-1}\right)$, and $\alpha$ is the uptake flux constant $(\mu \mathrm{mol}$ $\mathrm{kg}^{-1}$ worm $\left.\mathrm{d}^{-1}\right)$, which equals $k_{\mathrm{u}} C_{\mathrm{pw}}$, where $k_{\mathrm{u}}$ is the uptake rate constant $\left(\mathrm{L} \mathrm{kg}^{-1}\right.$ worm $\left.\mathrm{d}^{-1}\right)$ and $C_{\mathrm{pw}}$ is the bioavailable external concentration in pore water $\left(\mu \mathrm{mol} \mathrm{L}{ }^{-1}\right)$. The concentration of $\mathrm{CIP}$ or $\mathrm{Cd}$ in earthworms at the beginning of the experiment, $Q_{0}$, was assumed to be a pool of constant magnitude.

Once transferred to uncontaminated soil, Cd or CIP concentrations in earthworms varied with time according to the following equation:

$$
Q_{t}=Q_{e}+\left(Q_{t_{c}}-Q_{e}\right) e^{-k_{e}\left(t-t_{c}\right)}
$$

where $Q_{e}$ is the residue concentration of chemical in earthworms $\left(\mu \mathrm{mol} \mathrm{kg}{ }^{-1}\right.$ worm $)$ at the end of the elimination period (day 19) and $Q_{t_{c}}$ is the chemical concentration in earthworms ( $\mu \mathrm{mol}$ $\mathrm{kg}^{-1}{ }_{\text {worm }}$ ) at the end of the accumulation period (day 7$) \cdot t_{\mathrm{c}}$ is the time (d) at which earthworms were transferred to the clean pot, and $t$ is the time (d) since the beginning of the experiment. Subsequently, eq 1 was used to calculate steady-state tissue $\mathrm{Cd}$ concentrations $\left(C_{\mathrm{ss}}\right)$ for earthworms, which equals the ratio of the uptake flux constant to the elimination constant $\left(\alpha / k_{\mathrm{e}}\right)$. The steady-state concentrations were used to calculate bioaccumulation factors (the ratio of the metal concentration in earthworms to the pore water metal concentration, $\mathrm{BAF}_{\mathrm{pw}}$ ).

Data Analysis. All statistical analyses were conducted with the software SPSS 11.5 for Windows (SPSS Inc., Chicago, IL). Oneway ANOVA was used to assess the significance of the difference between groups, and nonlinear regression analyses were conducted by the least-squares method. Statements of significant differences are based on $P<0.05$.

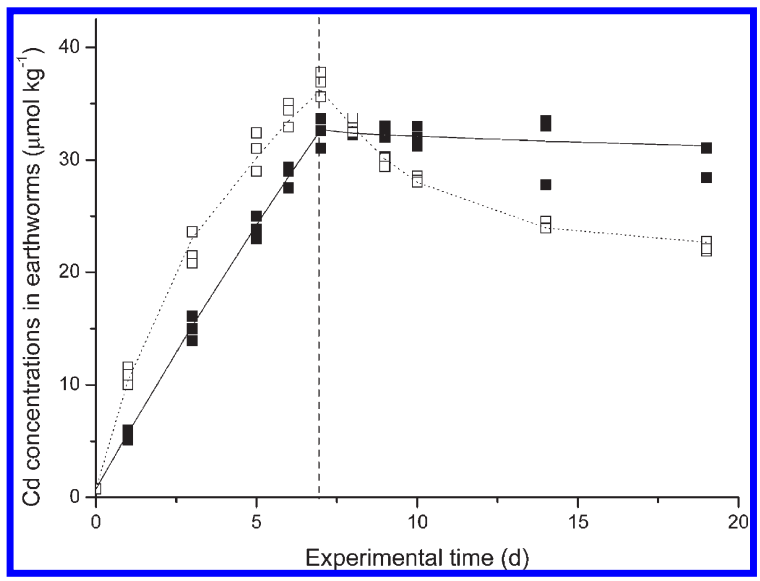

Figure 2. Accumulation and elimination kinetics of $\mathrm{Cd}$ in earthworms in the absence (solid squares) and in the presence (hole squares) of ciprofloxacin. Solid line: fits to eqs 1 and 2 for the uptake and elimination in the absence of ciprofloxacin, respectively. Dotted line: fits to eqs 1 and 2 for the uptake and elimination in the presence of ciprofloxacin, respectively.

\section{RESULTS}

Determination of the $\mathrm{Cd}^{2+}$ Concentration in Pore Water in the Presence of CIP. The concentration of $\mathrm{Cd}^{2+}$ in solutions measured by Cd-ISE was $49.6 \pm 0.9 \mu \mathrm{mol} \mathrm{L}^{-1}$. In the presence of $100 \mu \mathrm{mol} \mathrm{L}{ }^{-1} \mathrm{CIP}$, the concentration of $\mathrm{Cd}^{2+}$ in pore water was $36.4 \pm 0.2 \mu \mathrm{mol} \mathrm{L}^{-1}$.

Accumulation and Elimination of CIP and Cd. In the $19 \mathrm{~d}$ experiment, all earthworms had a healthy appearance, and no mortality occurred. The average wet weight loss was from $5 \%$ to $31 \%$, with varying time. No significant difference of weight losses between $\mathrm{Cd}$ and the mixture of $\mathrm{Cd}$ and CIP exposure was found. The initial concentration of CIP in earthworms was under the detection limit, while that for Cd was $0.075 \mu \mathrm{mol} \mathrm{kg}{ }^{-1}$.

Accumulation and Elimination of CIP with and without Cd. During the exposure phase, the uptake of CIP by earthworms was nonlinear for all treatments (Figure 1). There was no significant difference of CIP uptake by earthworms between the presence and absence of $\mathrm{Cd}$. During the $12 \mathrm{~d}$ depuration period, the concentration of CIP in earthworms decreased gradually. About $80 \%$ of the CIP in earthworms was lost, and the concentrations of $\mathrm{CIP}$ at the end were $2.76 \pm 0.20$ and $3.06 \pm 0.16 \mu \mathrm{mol} \mathrm{kg}^{-1}$ with and without $\mathrm{Cd}$, respectively.

The individual uptake and elimination data of CIP fitted eqs 1 and 2, respectively, well, with high $R^{2}$ values $(>0.97)$ and low mean weighted square error (MWSE; Figure 1 ; Table 1 ). The $k_{\mathrm{e}}$ values calculated from eq 1 were consistent with those calculated from eq 2 , showing the validity of the estimation. The uptake flux constant $\alpha$ and the elimination rate constant $k_{\mathrm{e}}$ values calculated for experiments without $\mathrm{Cd}$ were in the range of those with $\mathrm{Cd}$, respectively. These equivalent values resulted in similar values of $C_{\mathrm{ss}}$.

Accumulation and Elimination of $C d$ with and without CIP. The uptake of $\mathrm{Cd}$ did not reach saturation during the $7 \mathrm{~d}$ uptake period (Figure 2). In the absence of CIP, the Cd concentration in earthworms increased almost linearly with exposure time. The linear shape of the curve indicated a low rate of excretion. No significant decrease of $\mathrm{Cd}$ concentration in earthworms was found during the depuration period. The average $\mathrm{Cd}$ concentration in earthworms was about $91 \%$ of that at the end of accumulation. 
Table 1. Estimates of Kinetic Parameters for CIP and Cd Accumulation and Elimination

\begin{tabular}{|c|c|c|c|c|c|c|c|c|c|c|c|}
\hline \multirow[b]{2}{*}{ treatment } & \multicolumn{8}{|c|}{ calculated from eq 1} & \multicolumn{3}{|c|}{ calculated from eq 2} \\
\hline & $\alpha^{a}$ & $k_{\mathrm{u}}{ }^{b}$ & $k_{\mathrm{e}}^{c}$ & $C_{\mathrm{ss}}{ }^{d}$ & $t_{\mathrm{ss}}{ }^{e}(\mathrm{~d})$ & BAF $_{\mathrm{pw}}{ }^{f}$ & $R^{2}$ & MWSE $^{g}$ & $k_{\mathrm{e}}^{c}$ & $R^{2}$ & MWSE $^{g}$ \\
\hline \multicolumn{12}{|c|}{ CIP } \\
\hline CIP & $5.168 \pm 0.318$ & 0.0517 & $0.312 \pm 0.032$ & 16.56 & 17.13 & 0.166 & 0.986 & 0.0061 & $0.305 \pm 0.012$ & 0.992 & 0.013 \\
\hline $\mathrm{Cd}-\mathrm{CIP}$ & $5.496 \pm 0.255$ & 0.0550 & $0.323 \pm 0.024$ & 16.63 & 17.52 & 0.166 & 0.992 & 0.0088 & $0.321 \pm 0.023$ & 0.995 & 0.010 \\
\hline \multicolumn{12}{|c|}{$\mathrm{Cd}$} \\
\hline $\mathrm{Cd}$ & $5.040 \pm 0.219$ & 0.101 & $0.029 \pm 0.015$ & 173.8 & 187.9 & 3.476 & 0.995 & 0.0110 & $0.0403 \pm 0.035$ & 0.358 & 0.034 \\
\hline $\mathrm{Cd}-\mathrm{CIP}$ & $11.06 \pm 0.745$ & 0.221 & $0.286 \pm 0.022$ & 38.67 & 19.57 & 0.832 & 0.992 & 0.0072 & $0.303 \pm 0.016$ & 0.975 & 0.007 \\
\hline \multicolumn{12}{|c|}{$\begin{array}{l}{ }^{a} \text { The units are } \mu \mathrm{mol} \mathrm{kg}{ }^{-1}{ }_{\text {worm }} \mathrm{d}^{-1} \cdot{ }^{b} \text { Based on the total } \mathrm{Cd} \text { in solution; the units are } \mathrm{L} \mathrm{kg}^{-1} \text { worm } \mathrm{d}^{-1} \cdot{ }^{c} \text { The units are } \mathrm{d}^{-1} \cdot{ }^{d} \text { Calculated steady-state metal } \\
\text { concentration, } \mu \mathrm{mol} \mathrm{kg}{ }^{-1} \text { worm. }{ }^{e} \text { Calculated time taken to reach the steady state, d. }{ }^{f} \text { Bioaccumulation factor, which is calculated by the ratio of } C_{\mathrm{ss}} \text { to } \\
\text { the pore water metal concentration. }{ }^{g} \text { Mean weighted square error, equal to } 1 / v \Sigma\left[\left(q_{\text {measured }}-q_{\text {model }}\right)^{2} / q^{2} \text { measured }\right] \text {, where } v \text { is the amount of freedom; } \\
v=N-2 \text { for eq } 1 \text {, while } v=N-1 \text { for eq } 2 \text {. }\end{array}$} \\
\hline
\end{tabular}

In the presence of CIP, Cd showed different accumulation patterns (Figure 2). The Cd concentration in earthworms after 7 $\mathrm{d}$ uptake was 1.1 times that in the absence of CIP. The uptake curve was nonlinear, indicating the presence of significant elimination of $\mathrm{Cd}$. About $39.4 \% \mathrm{Cd}$ in earthworms was excreted during the depuration experiment.

The individual uptake and elimination data of $\mathrm{Cd}$ fitted eqs 1 and 2, respectively, well, except the Cd excretion in the absence of CIP (Figure 2, Table 1). The estimated uptake flux constant $\alpha$ of Cd with CIP was 2.2 times higher than that without CIP. The $k_{\mathrm{e}}$ value of $\mathrm{Cd}$ with CIP estimated from eq 1 was 9.8 times that without CIP, suggesting that CIP would enhance the elimination of $\mathrm{Cd}$ from earthworms. In the presence of CIP, the $k_{\mathrm{e}}$ value of Cd was consistent with the $k_{\mathrm{e}}$ value of CIP. The $C_{\mathrm{ss}}$ value without CIP was 4.49 times that with CIP (Table 1).

Subcellular Distribution over Time of CIP and Cd in Earthworms. To evaluate the validity of the fractionation and determination performance, earthworms were subjected to fractionation and subsequent determination of $\mathrm{Cd}$ and CIP. The relative standard deviations of $\mathrm{Cd}$ and $\mathrm{CIP}$ concentrations for six replicated determinations in fractions $\mathrm{D}, \mathrm{E}$, and $\mathrm{C}$ were in the range of $4.5-14.3 \%$. The sums of $\mathrm{Cd}$ and CIP in the three fractions were comparable with the total Cd and CIP in earthworms, thereby showing the validity of the fractionation and determination performance (Table S1, Supporting Information). The concentrations of CIP associated with fractions D, E, and C were found to be $0.22 \pm 0.01,0.14 \pm 0.02$, and $13.91 \pm 0.94$ $\mu \mathrm{mol} \mathrm{kg}^{-1}$, respectively. The presence of Cd did not change the subcellular distribution of CIP (data not shown).

The subcellular partitioning of Cd among fractions D, E, and C following $7 \mathrm{~d}$ exposure and $12 \mathrm{~d}$ elimination is shown in Figure S1, Supporting Information. In the absence of CIP, the concentrations of $\mathrm{Cd}$ associated with fractions $\mathrm{D}, \mathrm{E}$, and $\mathrm{C}$ were found to be $1.40,2.33$, and $28.0 \mu \mathrm{mol} \mathrm{kg}^{-1}$ at the end of the $7 \mathrm{~d}$ exposure, respectively. In the presence of CIP, the contents of $\mathrm{Cd}$ associated with fractions $\mathrm{D}$ and $\mathrm{E}$ decreased, while those associated with fraction $\mathrm{C}$ increased. Cadmium uptake and elimination could be described by eqs 1 and 2, respectively $\left(R^{2}>0.980\right.$, Table 2). The derived parameters showed that, in the absence of CIP, the $k_{\mathrm{e}}$ values of Cd in the D and E fractions were higher than zero, while that in fraction $\mathrm{C}$ was lower than zero, revealing the nonelimination of $\mathrm{Cd}$ from the $\mathrm{C}$ fraction. In the presence of CIP, the $k_{\mathrm{e}}$ values of $\mathrm{Cd}$ for fractions $\mathrm{D}$ and $\mathrm{E}$ did not change significantly, whereas the $k_{\mathrm{e}}$ value for fraction $\mathrm{C}$ increased to $0.303 \pm 0.040 \mathrm{~d}^{-1}$. This value was equal to the $k_{\mathrm{e}}$ values of CIP. A good relationship was found between the elimination of CIP and that of Cd $(p<0.01)$.

\section{DISCUSSION}

Possibility of Cd-CIP Complex Formation in Solution. Ciprofloxacin is one of the quinolone antibiotics. The composition of the quinolone complex was reported to be $1: 1$ for $\mathrm{Mn}, \mathrm{Zn}$, $\mathrm{Co}$, and Ni cations, with the apparent complex constant $\log K_{\mathrm{f}}$ values in the range of $3.3-4.6$. $^{15}$ Results of Wallis et al. ${ }^{16}$ showed that the addition of CIP to $\mathrm{Cu}$ formed $\mathrm{CuCIP}$ and $\mathrm{Cu}(\mathrm{CIP})_{2}$ complexes in a stepwise manner, and their formation constants were $\log K_{1}=6.2$ and $\log K_{2}=11.1$. The crystal of the $\mathrm{Cd}$ and CIP complex was synthesized, and both $1: 1$ and 1:2 complexes were formed between $\mathrm{Cd}$ and CIP. ${ }^{17,18}$ However, the apparent formation constant between CIP and Cd has not been found in the literature, limiting the performance of CIP and Cd chemical speciation calculation using computer programs. Nevertheless, in this study, ISE measurement showed that the free $\mathrm{Cd}^{2+}$ concentration decreased as a result of CIP addition, which suggested the complexation between $\mathrm{Cd}(\mathrm{II})$ and CIP.

Uptake and Elimination of CIP by Earthworms in the Presence of $\mathrm{Cd}$. So far, varying and even controversial results have been reported concerning the effect of metals on the accumulation and toxicity of quinolones. ${ }^{5}$ The ability of quinolones to penetrate into cells is a function of their net charge. The molecule in zwitterionic form exhibits the maximum permeation ability, whereas the uptake is strongly reduced when the drug bears a net charge as a result of ionization or complex formation with divalent ions. ${ }^{19}$ However, many quinolones possess modified pharmacological and toxicological properties when administered in the form of metallic complexes. When CIP is complexed with $\mathrm{Cu}(\mathrm{II}), \mathrm{Ni}(\mathrm{II}), \mathrm{Co}(\mathrm{II})$, and $\mathrm{Zn}$ (II), the uptake and toxicity of the complexes increases compared to those of the free CIP. ${ }^{20}$ In this study, no significant difference of the CIP uptake and elimination rate constants was found between different treatments, which suggested that the presence of $\mathrm{Cd}$ did not affect the bioaccumulation of CIP by earthworms.

Uptake and Elimination of $\mathrm{Cd}$ by Earthworms in the Presence of CIP. Numerous studies have investigated the relationship between metal speciation in the surrounding medium and metal accumulation in an organism. According to the free ion activity model (FIAM), the free metal ion activity reflects 
Table 2. Uptake and Elimination Kinetic Parameters of Cd in Various Subcellular Fractions of Earthworms Estimated from eqs 1 and 2

\begin{tabular}{|c|c|c|c|c|c|c|c|c|}
\hline \multirow[b]{2}{*}{ fraction } & \multicolumn{5}{|c|}{ calculated from eq 1} & \multicolumn{3}{|c|}{ calculated from eq 2} \\
\hline & treatment & $\alpha\left(\mu \mathrm{mol} \mathrm{kg}^{-1}{ }_{\text {worm }} \mathrm{d}^{-1}\right)$ & $k_{\mathrm{e}}\left(\mathrm{d}^{-1}\right)$ & $R^{2}$ & MWSE $^{a}$ & $k_{\mathrm{e}}\left(\mathrm{d}^{-1}\right)$ & $R^{2}$ & $\operatorname{MWSE}^{a}$ \\
\hline \multirow[t]{2}{*}{$\mathrm{D}$} & $\mathrm{Cd}$ & $0.357 \pm 0.012$ & $0.186 \pm 0.014$ & 0.999 & 0.0006 & $0.348 \pm 0.010$ & 0.998 & 0.0003 \\
\hline & $\mathrm{Cd}+\mathrm{CIP}$ & $0.220 \pm 0.026$ & $0.187 \pm 0.044$ & 0.993 & 0.0061 & $0.351 \pm 0.017$ & 0.994 & 0.0026 \\
\hline \multirow[t]{2}{*}{$\mathrm{E}$} & $\mathrm{Cd}$ & $0.708 \pm 0.058$ & $0.123 \pm 0.032$ & 0.996 & 0.0043 & $0.168 \pm 0.023$ & 0.965 & 0.0060 \\
\hline & $\mathrm{Cd}+\mathrm{CIP}$ & $0.488 \pm 0.076$ & $0.125 \pm 0.061$ & 0.986 & 0.0156 & $0.161 \pm 0.013$ & 0.995 & 0.0127 \\
\hline \multirow[t]{2}{*}{ C } & $\mathrm{Cd}$ & $3.384 \pm 0.301$ & $-0.006 \pm 0.026^{b}$ & 0.997 & 0.0058 & $-0.028 \pm 0.134^{b}$ & 0.035 & 0.0012 \\
\hline & $\mathrm{Cd}+\mathrm{CIP}$ & $12.51 \pm 0.97$ & $0.303 \pm 0.040$ & 0.996 & 0.0009 & $0.316 \pm 0.008$ & 0.998 & 0.0002 \\
\hline
\end{tabular}

${ }^{a}$ Mean weighted square error, equal to $1 / v \Sigma\left[\left(q_{\text {measured }}-q_{\text {model }}\right)^{2} / q^{2}\right.$ measured $]$, where $v$ is the amount of freedom; $v=N-2$ for eq 1 , while $v=N-1$ for eq $2 .{ }^{b}$ Negative values of the excretion rates $\left(k_{\mathrm{e}}\right)$ should be biologically considered as zero values.

the chemical reactivity of the metal, the extent to which the metal reacts with the binding sites on the cell membrane surface, and hence its bioavailability. ${ }^{21}$ In this study, the $\mathrm{Cd}^{2+}$ concentration in pore water decreased to $72.8 \%$ of the total $\mathrm{Cd}$ concentration after CIP was added. This decrease by a factor of 1.36 resulted in a decrease of the estimated $C_{\mathrm{ss}}$ value from 173.8 to $38.7 \mu \mathrm{mol}$ $\mathrm{kg}^{-1}$, which corresponds to a decrease by a factor of 4.5 . This implies that Cd uptake will be much lower than that predicted by the FIAM. However, results obtained from uptake and elimination experiments showed that the $C_{\mathrm{ss}}$ value decrease was due to the elevation of the $k_{\mathrm{e}}$ value, not the reduction of the $k_{\mathrm{u}}$ value. Indeed, in the presence of CIP, the estimated $\alpha$ value of Cd was 2.2 times higher than that in the absence of CIP. These results were in a clear contradiction with the FIAM.

It has also been reported occasionally that the FIAM is not always able to quantitatively relate metal speciation and bioavailability in the presence of ligand. ${ }^{8,22,23}$ Rate-limited diffusion of free metal ions to the cell surface ${ }^{9}$ and direct uptake of intact metal complexes ${ }^{22-24}$ are two explanations for these deviations. In this study, once the Cd and CIP complexes were formed, the polarity of the $\mathrm{Cd}$ ion was reduced to a greater extent due to the overlap of the ligand orbital and partial sharing of the positive charge of the $\mathrm{Cd}$ ion with the donor groups. The formation of complexes enhances the lipophilicity of $\mathrm{Cd}$. The reduced polarity may lead to increases of the $\mathrm{Cd}$ diffusion to the earthworm surface sites, while the enhanced lipophilicity may result in the possibility of complex penetration through the cell lipid membranes. The uptake of CIP by earthworms indicated that uptake of $\mathrm{Cd}-\mathrm{CIP}$ complexes is at least partly responsible for the higher uptake of Cd observed in the presence of CIP.

Spurgeon and Hopkin ${ }^{14}$ showed a slow and negligible excretion of Cd when earthworms were exposed to contaminated soils, suggesting that $\mathrm{Cd}$ is detoxified by storage rather than excretion. Similar phenomena of very slow Cd excretion from earthworms were reported by Veltman et al. ${ }^{25}$ and Nahmani et al. ${ }^{12}$ In this study, in the absence of CIP, the Cd elimination rate constant was much lower, in the range of those reported for earthworms exposed to laboratory-contaminated soils $\left(0.018-0.081 \mathrm{~d}^{-126,27}\right)$. This extremely low elimination led to an almost linear uptake curve (Figure 2).

Nahmani et al. ${ }^{12}$ suggested that the metal elimination rate constant is a property intrinsic to the organism and is not influenced by external factors. However, results obtained in this experiment showed that, in the presence of CIP, the Cd excretion rate increased significantly, leading to the nonlinear uptake curve (Figure 2) and low $C_{\mathrm{ss}}$ value of Cd (Table 1). These different accumulation patterns reflected the different biological responses of earthworms when exposed to $\mathrm{Cd}$ and a mixture of $\mathrm{Cd}$ and $\mathrm{CIP}$. Increases of metal elimination in the treatment of ligand have been reported; however, none of them concerned the effect of coexposure of the metal and ligand on the metal elimination kinetics. The feeding of EDTA significantly enhanced the excretion of $\mathrm{Zn}$ and $\mathrm{Cd}$ from fish. ${ }^{28,29}$ In this study, the increased $\mathrm{Cd}$ elimination rate constant in the treatment of $\mathrm{Cd}$ and CIP was equivalent to that of CIP. This finding indicated that $\mathrm{Cd}$ may be eliminated as the Cd-CIP complex.

Subcellular Distribution over Time of $\mathrm{Cd}$ in earthworms. Earthworms detoxify metals by sequestrating them and preventing their interaction with important biomolecules. ${ }^{30}$ The sequestration mechanisms include metal binding to proteins and other ligands and storage in the inorganic matrix of granules. ${ }^{11}$ The accumulation and elimination kinetics can be explained by partitioning of metals inside an organism. ${ }^{31,32}$ In this study, Cd in earthworms was separated into fractions $\mathrm{D}, \mathrm{E}$, and $\mathrm{C}$ and found mainly in fraction $\mathrm{C}$. Fraction $\mathrm{C}$ involves the binding of metals to some specific metal-binding proteins, such as metallothionein (MT) and other ligands. Metallothionein is reported to be induced by $\mathrm{Cd}$ and plays an important role in metal detoxification, storage, and homeostasis in animals. ${ }^{33}$ The results of $\mathrm{Cd}$ tightly bound in the $\mathrm{C}$ fraction and low elimination of $\mathrm{Cd}$ from the $C$ fraction were reported for terrestrial organisms. ${ }^{1,26,32}$ Li et al. ${ }^{26}$ separated $\mathrm{Cd}$ in earthworms into $\mathrm{D}, \mathrm{E}$, and $\mathrm{C}$ fractions and further separated fraction $C$ into $G$ (intact cell) and F (the organelles) fractions. They suggested that, for $\mathrm{Cd}$ in earthworms, there are at least two different types of binding sites at the subcellular level, low-affinity and high-affinity. Fractions D and E, representing low-affinity binding sites, showed a nonlinear uptake curve, and fractions $\mathrm{G}$ and $\mathrm{F}$, representing high-affinity binding sites, were responsible for the linear accumulation pattern. Nonexcretion of $\mathrm{Cd}$ from the $\mathrm{C}$ fraction of snails was also reported. ${ }^{32}$

In the presence of CIP, the amount of $\mathrm{Cd}$ in the $\mathrm{C}$ fraction increased, while that in the $\mathrm{D}$ and $\mathrm{E}$ fractions decreased, revealing that CIP could change the subcellular distribution patterns of Cd in earthworms. In contrast to the nonelimination of $\mathrm{Cd}$ from the $\mathrm{C}$ fraction in the absence of CIP, Cd in fraction $\mathrm{C}$ was eliminated obviously in the presence of CIP, indicating the loose binding between $\mathrm{Cd}$ and some proteins and/or the existence of different speciation of $\mathrm{Cd}$ in fraction C. Kargin ${ }^{28}$ found that Cd exposure of fish (Tilapia zilli) caused increases in total protein concentrations in liver. After EDTA treatment, the induced protein concentrations in liver decreased, and the $\mathrm{Cd}$ in fish was 
eliminated obviously. The author attributed the higher elimination of Cd from fish (T. zilli) in the presence of EDTA to the decrease of metal-binding proteins induced and the loss of metal binding with proteins (such as MT) in fish liver. Ligand substitution reaction between EDTA and Cd-MT was demonstrated by Gan et al. ${ }^{34}$ In this study, more than 95\% CIP in earthworms was presented in fraction $\mathrm{C}$ due to its hydrophilic nature. Thus, it is deduced that the existence of the Cd-CIP complex in fraction $\mathrm{C}$ is one of the important factors responsible for the loose binding between $\mathrm{Cd}$ and some proteins in fraction $\mathrm{C}$ as a result of CIP treatment. A good relationship was found between the excretion of CIP in the presence of $\mathrm{Cd}$ and the excretion of $\mathrm{Cd}$ in the presence of CIP from fraction $\mathrm{C}(p<$ 0.001), implying that $C d$ could be eliminated from earthworms as the Cd-CIP complex.

The results from this study showed that CIP and Cd could form a complex in the pore water. The presence of $\mathrm{Cd}$ had little influence on the uptake and elimination kinetics of CIP in earthworms. However, Cd exhibited different metabolic patterns for earthworms in the treatments with and without CIP. The above evidence indicated that earthworms could take up, store, and eliminate, at least partly, the Cd-CIP complexes. These findings help to understand the uptake mechanism and interactions of CIP and Cd in earthworms, although an exact explanation for the observed effect remains to be provided. Further studies should be taken to detail the physiological responses of earthworms when exposed to the mixture of CIP and Cd.

\section{ASSOCIATED CONTENT}

S Supporting Information. Table showing the sum of $\mathrm{Cd}$ and CIP in the three fractions and figure showing the accumulation and elimination kinetics of $\mathrm{Cd}$ in subcellular fractions in the absence and presence of CIP. This material is available free of charge via the Internet at http://pubs.acs.org.

\section{AUTHOR INFORMATION}

\section{Corresponding Author}

*Phone: + 86-10-62849329; fax: + 86-10-62923563; e-mail: bwen@rcees.ac.cn.

\section{ACKNOWLEDGMENT}

This work was funded by the National Natural Science Foundation of China (Projects 20737003, 40730740, and 20877087).

\section{REFERENCES}

(1) Nicholson, F. A.; Smith, S. R.; Alloway, B. J.; Carlton-Smith, C.; Chambers, B. J. An inventory of heavy metals inputs to agricultural soils in England and Wales. Sci. Total Environ. 2003, 311, 205-219.

(2) Luo, L.; Ma, Y. B.; Zhang, S. Z.; Wei, D. P.; Zhu, Y. G. An inventory of trace element inputs to agricultural soils in China. I. Environ. Manage. 2009, 90, 2524-2530.

(3) Picó, Y.; Andreu, V. Fluoroquinolones in soil-risks and challenges. Anal. Bioanal. Chem. 2007, 387, 1287-1299.

(4) Sarmah, A. K.; Meyer, M. T.; Boxall, A. B. A. A global perspective on the use, sales, exposure pathways, occurrence, fate and effects of veterinary antibiotics (VAs) in the environment. Chemosphere 2006, $65,725-759$.

(5) Turel, I. The interactions of metal ions with quinolone antibacterial agents. Coord. Chem. Rev. 2002, 232, 27-47.
(6) Höffken, G.; Borner, K.; Glatzel, P. D.; Koeppe, P.; Lode, H. Reduced eternal absorption of ciprofloxacin in the presence of antacids. Eur. I. Clin. Microbiol. 1985, 4, 345-349.

(7) Bayen, S.; Worms, I.; Parthasarathy, N.; Wilkinson, K.; Buffle, J. Cadmium bioavailability and speciation using the permeation liquid membrane. Anal. Chim. Acta 2006, 575, 267-273.

(8) Degryse, F.; Smolders, E.; Merck, R. Labile Cd complexes increase Cd availability to plants. Environ. Sci. Technol. 2006, 40, $830-836$.

(9) Vijver, M. G.; Koster, M.; Peijnenburg, W. J. G. M. Impact of pH on $\mathrm{Cu}$ accumulation kinetics in earthworm cytosol. Environ. Sci. Technol. 2007, 41, 2255-2260.

(10) Huang, R. X.; Wen, B.; Pei, Z. G.; Shan, X. Q.; Zhang, S. Z.; Williams, P. N. Accumulation, subcellular distribution and toxicity of copper in earthworm (Eisenia fetida) in the presence of ciprofloxacin. Environ. Sci. Technol. 2009, 43, 3688-3693.

(11) Vijver, M. G.; van Gestel, C. A. M.; van Straalen, N. M.; Lanno, R. P.; Peijnenburg, W. J. G. M. Biological significance of metals partitioned to subcellular fractions within earthworms (Aporrectodea caliginosa). Environ. Toxicol. Chem. 2006, 25, 807-814.

(12) Nahmani, J.; Hodson, M. E.; Devin, S.; Vijver, M. G. Uptake kinetics of metals by the earthworm Eisenia fetida exposed to fieldcontaminated soils. Environ. Pollut. 2009, 157, 2622-2628.

(13) Morrison, D. E.; Robertson, B. K.; Alexander, M. Bioavailability to earthworms of aged DDT, DDE, DDD, and dieldrin in soil. Environ. Sci. Technol. 2000, 34, 709-713.

(14) Spurgeon, D. J.; Hopkin, S. P. Comparisons of metal accumulation and excretion kinetics in earthworms (Eisenia fetida) exposed to contaminated field and laboratory soils. Appl. Soil Ecol. 1999, 11, 227-243.

(15) Park, H. R.; Kim, T. H.; Bark, K. M. Physicochemical properties of quinolone antibiotics in various environments. Eur. I. Med. Chem. 2002, 37, 443-460.

(16) Wallis, S. C.; Gahan, L. R.; Charles, B. G.; Hambley, T. W.; Duckworth, P. A. Copper(II) complexes of the fluoroquinolone antimicrobial ciprofloxacin. Synthesis, X-ray structural characterization, and potentiometric study. I. Inorg. Biochem. 1996, 62, 1-16.

(17) Anacona, J. R.; Toledo, C. Synthesis and antibacterial activity of metal complexes of ciprofloxacin. Transition Met. Chem. (Dordrecht, Neth.) 2001, 26, 228-231.

(18) Golovnev, N. N.; Kirik, S. D.; Golovneva, I. I.; Nishnevich, M. E. Synthesis and characterization of ciprofloxacin compounds with cadmium(II) and mercury(II) chlorides. Russ. I. Inorg. Chem. 2006, $51,415-420$.

(19) Valisena, S.; Palumbo, M.; Parolin, C.; Palú, G.; Meloni, G. A. Relevance of ionic effects on norfloxacin uptake by Escherichia coli. Biochem. Pharmacol. 1990, 40, 431-436.

(20) Imran, M.; Iqbal, J.; Iqbal, S.; Ijaz, N. In vitro antibacterial studies of ciprofloxacin-imines and their complexes with $\mathrm{Cu}$ (II), $\mathrm{Ni}$ (II), Co(II), and Zn(II). Turk. I. Biol. 2007, 31, 67-72.

(21) Morel, F. M. M. Principles of Aquatic Chemistry; John Wiley and Sons: New York, 1983.

(22) Chuang, C. Y.; Wang, W. X. Co-transport of metal complexes by the green mussel Perna viridis. Environ. Sci. Technol. 2006, 40, $4523-4527$.

(23) Boullemant, A.; Lavoie, M.; Fortin, C.; Campbell, P. G. C. Uptake of hydrophobic metal complexes by three freshwater algae: Unexpected influence of pH. Environ. Sci. Technol. 2009, 43, 3308-3314.

(24) Voets, J.; Bervoets, L.; Blust, R. Cadmium bioavailability and accumulation in the presence of humic acid to the zebra mussel, Dreissena polymorpha. Environ. Sci. Technol. 2004, 38, 1003-1008.

(25) Veltman, K.; Huijbregts, M. A. J.; Vijver, M. G.; Peijnenburg, W. J. G. M.; Hobbelen, P. H. F.; Koolhaas, J. E.; van Gestel, C. A. M.; van Vliet, P. C. J.; Jan Hendriks, A. Metal accumulation in the earthworm Lumbricus rubellus. Model predictions compared to field data. Environ. Pollut. 2007, 146, 428-436.

(26) Li, L. Z.; Zhou, D. M.; Wang, P.; Peijnenburg, W. J. G. M. Kinetics of cadmium uptake and subcellular partitioning in the 
earthworm Eisenia fetida exposed to cadmium-contaminated soil. Arch. Environ. Contam. Toxicol. 2009, 57, 718-724.

(27) Neuhauser, E. F.; Cukic, Z. F.; Malecki, M. R.; Loehr, R. C.; Durkin, P. R. Bioconcentration and biokinetics of heavy metals in the earthworm. Environ. Pollut. 1995, 89, 293-301.

(28) Kargin, F. Elimination of cadmium from Cd-contaminated Tilapia zilli in media containing EDTA and freshwater: Changes in protein levels. Bull. Environ. Contam. Toxicol. 1996, 57, 211-216.

(29) Muramoto, S. Reduction of Cd in a Cd-contaminated fish by long-term exposure to EDTA and fresh-water. I. Environ. Sci. Health 1982, 17, 67-74.

(30) Vijver, M. G.; van Gestel, C. A. M.; Lanno, R. P.; van Straalen, N. M.; Peijnenburg, W. J. G. M. Internal metal sequestration and its ecotoxicological relevance: A review. Environ. Sci. Technol. 2004, 38, 4705-4712.

(31) Pan, K.; Wang, W. Biodynamics to explain the difference of copper body concentrations in five marine bivalve species. Environ. Sci. Technol. 2009, 43, 2137-2143.

(32) Gimbert, F.; Vijver, M. G.; Coeurdassier, M.; Scheifler, R.; Peijnenburg, W. J. G. M.; Badot, P.; de Vaufleury, A. How subcellular partitioning can help to understand heavy metal accumulation and elimination kinetics in snails. Environ. Toxicol. Chem. 2008, 27, 12841292.

(33) Roesijadi, G. Metallothioneins in metal regulation and toxicity in aquatic animals. Aquat. Toxicol. 1992, 22, 81-114.

(34) Gan, T.; Munoz, M.; Shaw, C. F., III; Petering, D. H. Reaction of ${ }^{111} \mathrm{Cd}_{7}$-metallothionein with EDTA. L. Biol. Chem. 1995, 270, 53395345. 